\title{
EFFECT OF PHOTOPERIOD ON OVARIAN FUNCTION IN THE VOLE, MICROTUS AGRESTIS
}

\author{
W. G. BREED* AND J. R. GLARKE \\ Department of Agricultural Science, University of Oxford, \\ Oxford, $O X 138 F$ \\ (Received 4th May 1970)
}

It has been shown that photoperiod affects the reproductive development of the vole, Microtus agrestis, the ovaries and uteri weighing more in laboratorysimulated summer than in laboratory-simulated winter (Clarke \& Kennedy, 1967). Photoperiod has a similar effect on ovarian function in $M$. arvalis (Lecyk, 1962; Thibault, Courot, Martinet, Mauléon, du Mesnil du Buisson, Ortavant, Pelletier \& Signoret, 1966). In order to define more accurately the influence of light on the sexual development of $M$. agrestis, the effect of six different photoperiods on the onset of puberty and on ovarian activity in virgin voles after 8 weeks of treatment was investigated.

The experimental animals were the progeny of a breeding colony kept in the Department of Agricultural Science at Oxford. Females, 18 days old, were placed in light-proof cupboards (see Clarke \& Kennedy, 1967) and subjected to $8,10,12,14,16$ or $24 \mathrm{hr}$ light $/ 24 \mathrm{hr}$ for 56 days. Animals were inspected daily for vaginal perforation and smears were taken if this had occurred. The relative abundance of leucocytes, cornified and nucleated epithelial cells was recorded. At the end of the experiment, the animals were killed, uteri removed and weighed fresh, and ovaries weighed after fixation in Bouin's fluid. Ovaries were serially sectioned at $7 \mu$, stained with Ehrlich's haematoxylin and eosin, and Graafian follicles were measured and counted as described by Breed (1969). Data were subjected to analysis of variance and treatment means were compared by Duncan's multiple range test.

The age at which the vagina opened varied significantly between the different groups $(F=8 \cdot 10, P<0.001$; Table 1$)$; animals subjected to 14 or more hr light/day (long photoperiods) became perforate earlier than those on 12 or less hr light/day (short photoperiods). There were, however, no significant differences between the means within either the long or short photoperiods.

None of the vaginal smears indicated regular vaginal oestrous cycles, nor were there any clear-cut differences between treatments in the vaginal smear patterns. About half the females in each group had continuously cornified smears, whereas the remaining animals had mixtures of cornified and nucleated epithelial cells, with or without leucocytes.

* Present address: Department of Anatomy, Medical School, University of Birmingham, Birmingham B15 2TJ. 


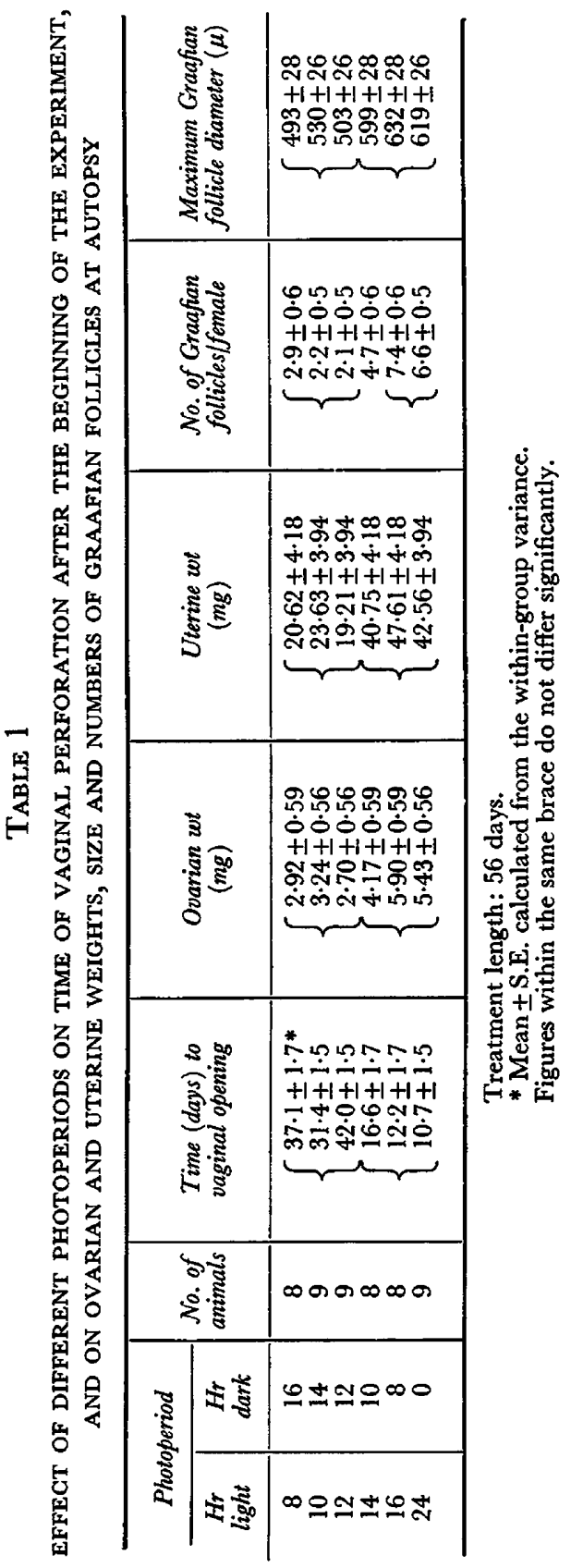


Treatments also had a significant effect on ovarian $(\mathbf{F}=5 \cdot 61, P<0 \cdot 001)$ and uterine weights $(\mathrm{F}=9.78, P<0.001)$; mean body weights were, however, unaffected and ranged from $28 \cdot 3 \pm 1.6$ to $31.5 \pm 1.5 \mathrm{~g}$. Mean ovarian and uterine weights for animals subjected to the long photoperiods were all significantly greater than those for animals subjected to the short photoperiods (Table 1), but within both the long and the short photoperiods, no significant differences between the means occurred. There were no corpora lutea in any ovaries but there was a significant effect of treatments on both the number $(F=16 \cdot 81$, $P<0.001)$ and maximum size $(\mathrm{F}=5.07, P<0.01)$ of the Graafian follicles (Table 1). In the 16- and 24-hr photoperiods, females had significantly more Graafian follicles than in all other groups. The number for the 14-hr photoperiod was also significantly greater than the number for the females subjected to the short photoperiods. The maximum sizes of Graafian follicles did not differ significantly within either the long or short photoperiods but, whereas the figure for the 16-hr photoperiod was significantly greater than those for all the short photoperiods, that for the 24-hr only differed significantly from the 12- and 8-hr and that for the 14-hr only from the 8-hr photoperiods.

These results indicate that the onset of puberty in female voles, as indicated by vaginal perforation, depends on the length of the photoperiod, 14 or more hr light inducing earlier maturation. Puberty was not, however, further accelerated by light regimens greater than $14 \mathrm{hr}$ light, nor was it retarded more by the two light regimens of less than $12 \mathrm{hr}$ light.

Similarly, it was found that, within the limits of this experiment, there was a threshold photoperiod greater than $12 \mathrm{hr}$ and less than $14 \mathrm{hr}$ light at and above which the reproductive organs were more activated. Clarke \& Kennedy (1967) exposed voles either to 6 or $16 \mathrm{hr}$ light for 84 days but there were no significant differences between treatments in the maximum follicular sizes. The greater duration of this earlier experiment may have permitted follicles in females on short days to develop, albeit more slowly, to the same size as those of animals on long days. Thus, short photoperiods appear to delay but do not prevent ovarian development.

The occurrence of larger ovaries with both more and larger follicles suggests that animals on long photoperiods had higher circulating levels of gonadotrophin. Ovariectomy in the vole results in a marked decrease in uterine weight and closure of the vagina, but daily subcutaneous injections of $0.01 \mu \mathrm{g}$ of oestrogen reverses these effects (Breed, 1968). The results obtained indicate that animals on 14 or more $\mathrm{hr}$ light/day secreted sufficient oestrogen to induce earlier vaginal perforation and the heavier uteri indicate higher levels of oestrogen at termination of the experiment. The lack of corpora lutea in all animals is consistent with other results showing that the vole is an induced ovulator (Austin, 1957; Breed, 1967).

We are indebted to Professor G. E. Blackman, F.R.s., for providing facilities and to Mrs J. Day, Mr F. Honey, Mr F. Roach and Mr A. Probitt for invaluable technical assistance. W.G.B. was a recipient of a Ministry of Agriculture, Fisheries and Food studentship. 


\section{REFERENCES}

Austin, C. R. (1957) Oestrus and ovulation in the field vole (Microtus agrestis). F. Endocr. 15, iv.

BREED, W. G. (1967) Ovulation in the Genus Microtus. Nature, Lond. 214, 826.

BREeD, W. G. (1968) Reproductive physiology of the female short-tailed field vole (Microtus agrestis) with special reference to ovarian function. D.Phil. thesis, Oxford University.

BREED, W. G. (1969) Oestrus and ovarian histology in the lactating vole, Microtus agrestis. F. Reprod. Fert. 18, 33.

CLARKE, J. R. \& KENNEDY, J. P. (1967) Effect of light and temperature upon gonad activity in the vole (Microtus agrestis). Gen. Eீ compar. Endocr. 8, 474.

LECYK, M. (1962) The effect of the length of daylight on reproduction in the field vole (Microtus arvalis Pall.). Zoologica Pol. 12, 189.

Thibault, G., Courot, M., Martinet, L., Mauléon, P., du Mesnil du Buisson, F., Ortavant, R., Pelletier, J. \& Signoret, J. P. (1966) Regulation of breeding season and estrous cycles by light and external stimuli in some mammals. F. Anim. Sci. 25, Suppl., 119. 